\title{
Avançando para tornar os sonhos possíveis
}

\author{
Heron Ferreira Souza ${ }^{1 *}$, Erasto Viana Silva Gama ${ }^{2}$
}

\begin{abstract}
${ }^{1}$ Editor Chefe da Revista
Macambira. Doutorado em Educação (Políticas, Administração e Sistemas Educacionais) pela Unicamp (2015). Mestrado em Educação e Contemporaneidade pela UNEB (2009). Licenciatura em Geografia pela Universidade do Estado da Bahia (2006). Professor do Instituto Federal Baiano, Campus Serrinha. Coordenador do Laboratório de Políticas Públicas, Ruralidades e Desenvolvimento Territorial LaPPRuDes. https://orcid.org/00000003-0927-3112
\end{abstract}

${ }^{2}$ Editor Adjunto da Revista Macambira. Engenheiro agrônomo e mestre em ciências agrárias (UFRB). Docente na área de agroecologia no Instituto Federal de Educação, Ciência e Tecnologia Baiano - Campus Serrinha. https://orcid.org/0000-00027970-4849

*Autor correspondente: heron.souza@ifbaiano.edu.br

\section{Resumo:}

Este é o editorial do volume 4, número 1 da Revista Macambira, periódico semestral do Laboratório de Políticas Públicas, Ruralidades e Desenvolvimento Territorial (LaPPRuDes), do Instituto Federal de Educação Ciência e Tecnologia Baiano (IF BAIANO). Apresentamos no texto as conquistas alcançadas nestes quatro anos de existência, as parcerias estabelecidas neste ano de 2020, a ampliação dos indexadores, a reformulação e ampliação do corpo editorial e científico, e a ampliação de quadro de pareceristas ad hoc. Por fim agradecemos todos e todas têm colaborado para todas estas conquistas e para ampliação da divulgação científica de qualidade e livre acesso. Convidamos os leitores e autores a submeterem seus trabalhos para a revista macambira que agora funciona em regime de publicação em fluxo contínuo.

Palavras-chave: Revista Macambira, IF Baiano, LaPPRuDes, Acesso aberto, v4n1.

REVISTA MACAMBIRA

Instituto Federal de Educação, Ciência e Tecnologia Baiano, campus Serrinha. Estrada Vicinal de Aparecida, s/n, Bairro Aparecida, Serrinha (Ba), CEP: 48700-000, sala 01, prédio acadêmico. 


\title{
Moving forward to make dreams possible
}

\author{
Heron Ferreira Souza ${ }^{1 *}$, Erasto Viana Silva Gama²
}

${ }^{1}$ Lead Editor of Macambira Journal. $\mathrm{PhD}$ in Education (Policies, Administration and Educational Systems) from Unicamp (2015). Master in Education and Contemporaneity from UNEB (2009). Degree in Geography at State University of Bahia (2006). Professor at the Federal Institute Baiano, Campus Serrinha. Coordinator of Laboratory of Public Policies, Ruralities and Territorial Development - LaPPRuDes. https://orcid.org/0000-0003-0927$\underline{3112}$

2 Deputy Editor of Macambira Journal. Agronomist and Master in Agrarian Sciences (UFRB). Professor at the Federal Institute Baiano, Campus Serrinha. https://orcid.org/0000-0002-7970$\underline{4849}$

*Autor correspondente: heron.souza@ifbaiano.edu.br

\section{Resumo:}

This is the foreword of volume 4, issue 1 of Macambira Journal, a biannual journal of the Laboratory of Public Policies, Ruralities and Territorial Development (LaPPRuDes), from Federal Institute of Education Science and Technology Baiano (IF BAIANO). In this text, we present the achievements in these four years of existence, the partnerships established in 2020, the expansion of the indexers, the editorial reformulation, as well as the expansion of the scientific body, and the ad hoc panel of reviewers. Finally, we would like to thank all those who have collaborated for the achievements we have accomplished and for the expansion of free and quality scientific dissemination. We also would like to invite the readers and authors to submit their papers to the magazine that adopts a continuous flow policy.

Keywords: Macambira Journal, IF Baiano, LaPPRuDes, Open acess, v4n1.

MACAMBIRA JOURNAL

Federal Institute of Education, Science and Technology Baiano, campus Serrinha. Estrada Vicinal de Aparecida, s/n, Bairro Aparecida, Serrinha, Bahia, Brasil, CEP: 48700-000, sala 01, prédio acadêmico. 
Chegamos ao quarto ano da Revista Macambira com importantes conquistas resultantes de um trabalho coletivo com o objetivo de garantir esse espaço qualificado de divulgação científica e tecnológica para os campos científicos e temáticas como a Agroecologia, Educação do Campo, Economia Solidária, Desenvolvimento e debates contemporâneos sobre Educação e Ensino.

Novas parcerias foram estabelecidas com pesquisadores nacionais e internacionais de modo a fortalecermos nosso caráter multidisciplinar com foco nos campos científicos priorizados na Revista Macambira. Esse movimento simboliza, em alguma medida, a necessidade de construir esse espaço de divulgação científica também como o lugar de encontro, problematizações, diálogos e aprendizagens com a diversidade que nos caracteriza enquanto país e continente latinoamericano.

$\mathrm{O}$ acesso livre às pesquisas que retratam a realidade vivida, principalmente, pelos povos do campo no tocante aos processos produtivos, relações de trabalho, acesso as políticas públicas e processos educativos escolares e não-escolares colabora com a construção de uma ciência ético-politicamente comprometida com a vida, os direitos humanos e a construção de melhorias técnicas e tecnológicas aos problemas dos grupos populares do campo e da cidade, sobretudo, relacionados aos processos organizativos, educativos, sócio-produtivos e ambientais.

É atendendo a estes preceitos que reafirmamos a missão da Revista Macambira em contribuir na construção de uma ciência popular, uma ciência da vida e da complexidade, do diálogo, a fim de contribuir com a reflexão e ação por um projeto autêntico de sociedade construído "desde baixo".

Do ponto de vista técnico, realizamos nos últimos anos mudanças significativas no site, atualização da plataforma OJS, aperfeiçoamento dos mecanismos de recebimento e publicação dos artigos aprovados a partir do chamado fluxo contínuo para cada número e, como mencionado anteriormente, recomposição do conselho editorial, conselho científico e avaliadores $A d$ hoc, nacionais e internacionais. Investimos ainda na indexação e estamos em processo de ampliação das bases indexadoras. Outras ações estão em curso para divulgação da Revista e dos trabalhos publicados. 
O conjunto destas ações dão concretude aos propósitos originários da Revista Macambira, mas também nos tem permitido construir outras relações, redes e nos colocar no movimento dos "sonhos possíveis". O ato revolucionário de esperançar não consiste em esperar, já dizia Paulo Freire. Requer construção de conhecimento científico e tecnológico e ação, num diálogo constante com os homens, mulheres, jovens, trabalhador@s do campo e da cidade no seu processo ampliado de produção da vida.

Esperamos que os leitores da Revista Macambira possam apreciar e valorizar as importantes contribuições aqui trazidas pelos autores.

Desejamos a todos e todas boa leitura e convidamos a realizar submissão de seus trabalhos a REVISTA MACAMBIRA através do site http://revista.lapprudes.net/index.php/RM.

\begin{tabular}{|c|c|}
\hline Informações do Artigo & Article Information \\
\hline $\begin{array}{l}\text { O editorial não é avaliado por pares. } \\
\text { Publicado em: 01/08/2020 }\end{array}$ & $\begin{array}{l}\text { The editorial is not peer-reviewed. } \\
\text { Published on: } 01 / 08 / 2020\end{array}$ \\
\hline $\begin{array}{l}\text { Conflitos de Interesse: Os autores declaram não } \\
\text { haver quaisquer conflitos de interesse referente a } \\
\text { este artigo. }\end{array}$ & Conflict of Interest: No reported. \\
\hline Como citar este artigo & How to cite this article \\
\hline $\begin{array}{l}\text { Souza, H. F.; GAMA, V. S. G. (2020). Avançando para } \\
\text { tornar os sonhos possíveis. Revista Macambira, 4(1), } \\
\text { e041008. https://doi.org/10.35642/rm.v4i1.479 }\end{array}$ & $\begin{array}{l}\text { Souza, H. F.; GAMA, V. S. G. (2020). Moving forward } \\
\text { to make dreams possible. Revista Macambira, } 4(1) \text {, } \\
\text { e041008. https://doi.org/10.35642/rm.v4i1.479 }\end{array}$ \\
\hline (c) & License: \\
\hline $\begin{array}{l}\text { Este trabalho está licenciado sob uma Licença } \\
\text { Internacional Creative Commons Attribution- } \\
\text { NonCommercial-ShareAlike } 4.0 \text { International. }\end{array}$ & $\begin{array}{l}\text { This work is licensed under a Creative Commons } \\
\text { Attribution-NonCommercial-ShareAlike } \\
\text { International License. }\end{array}$ \\
\hline
\end{tabular}

